DOI: https://doi.org/10.24867/12BE38Vujovic

\title{
INSPEKCIJA UPOTREBLJIVOSTI MOBILNIH APLIKACIJA ZA OČUVANJE ZDRAVLJA
}

\section{USABILITY INSPECTION OF MOBILE HEALTH APPS}

\author{
Nemanja Vujović, Fakultet tehničkih nauka, Novi Sad
}

\section{Oblast - ELEKTROTEHNIKA I RAČUNARSTVO}

Kratak sadržaj - U ovom radu opisan je problem inspekcije upotrebljivosti različitih mobilnih aplikacija za očuvanje zdravlja. Metod korišćen za ispitivanje je kognitivni prolazak, a na kraju je urađeno sumiranje dobijenih rezultata.

Ključne reči: Inspekcija, analiza, zdravlje, aplikacija

\begin{abstract}
This paper describes the problem of usability inspection of different Mobile Health apps. Examination is done by using Cognitive walkthrough method. In the end, a summary of obtained results is included in the paper.
\end{abstract}

Keywords: Inspection, analysis, health, application

\section{UVOD}

Zadatak ovog rada jeste inspekcija upotrebljivosti mobilnih aplikacija za očuvanje zdravlja. Pod samom inspekcijom podrazumeva se temeljna analiza zasebnih funkcionalnosti health aplikacija i poređenje dobijenih rezultata. Samo određen broj funkcionalnosti će biti ispitan, a izbor će se vršiti na osnovu njihove važnosti, kao i na osnovu toga koliko se često koriste u odnosu na ostale funkcionalnosti u aplikaciji. To zapravo znači da će one najfrekventnije biti ispitane, dok one manje važne neće.

Funkcionalnosti koje će biti podvrgnute inspekciji su: izbor aktivnosti i načina vežbanja, povezivanje sa drugim uređajima i dnevni unos kalorija. Tehnika koja će biti korišćena za analizu jeste Cognitive walkthrough, odnosno kognitivni prolazak. Konačni rezultati biće prikazani tabelarno uz pomoć tablice kognitivnog prolaska, dok će svaka ispitana funkcionalnost biti potkrepljena odgovarajućom slikom.

Cilj ovog istraživanja jeste upoznavanje sa načinom rada, kao i pronalazak mogućih unapređenja za Mobile Health aplikacije. Kao modeli za inspekciju biće korišćene aplikacije Samsung health i Huawei health. Razlog ovog izbora leži u tome što su date aplikacije najpopularnije i najkvalitetnije na tržištu i kao takve najbolji su primer funkcionisanja mobilnih aplikacija za očuvanje zdravlja. Pored same analize i poređenja dveju aplikacija, odnosno njihovih određenih funkcionalnosti, ovaj rad će se u manjoj meri baviti i opisom tehnika za ispitivanje upotrebljivosti aplikacija, kao i razlozima zbog kojih je $u$ ovom radu izabrana tehnika Cognitive walkthrough.

\section{NAPOMENA:}

Ovaj rad proistekao je iz master rada čiji mentor je bio dr Dragan Ivetić, red. prof.

\section{MOTIVACIJA I OPIS PROBLEMA}

Motivacija za pisanje ovakve vrste rada leži u velikom broju razloga. Jedan od njih jeste sam razvoj tehnologije u poslednjih nekoliko godina. Svaka grana života pokrivena je odgovarajućom tehnologijom. Poseban napredak $u$ poslednje vreme beleži proizvodnja mobilnih telefona, čiji osnovni sadržaj čine android aplikacije.

Jedna vrsta tih aplikacija su i aplikacije za očuvanje zdravlja, čijom analizom će se ovaj rad baviti. Dakle, potreba za stalnim unapređivanjem tehnologije, u ovom slučaju android-a, je glavni motiv pisanja ovog rada. Sam rad bi trebao da ponudi detaljnu analizu ove vrste aplikacija i da ukaže na eventualne nedostatke. Pored toga trebao bi predstaviti određena rešenja problema, ne programskim putem, ali kao neku ideju svakako. Osim napretka tehnologije i potrebe za unapređivanjem aplikacija, motiv za pisanje ove teme je i velika potreba čoveka za zdravljem, ali i za dobrim izgledom.

Veliku pomoć u datim potrebama omogućavaju health aplikacije. Svaki korisnik health-a može na vrlo jednostavan način da isprati rad svoga tela za vreme vežbanja, što je pomoć kakvu čovek ranije nije imao. Dodatne mogućnosti koje ove vrste aplikacija nude su i pomoć pri izboru aktivnosti kao i praćenje unosa kalorija. Korisnik može da izabere jednu od ponuđenih aktivnosti, kao što su: šetanje, trčanje, plivanje ili recimo vožnja biciklom i da na osnovu svoga vežbanja isprati rezultate. Kada je reč o unosu kalorija, aplikacija nudi opciju pravljenja obroka, koji bi trebao da se u potpunosti poklapa sa stvarnim obrokom datog korisnika i da na osnovu vrednosti makronutrijenata, namirnica koje su u taj obrok ubačene, izračuna količinu unešenih kalorija u okviru tog konkretnog obroka. Aplikacije za očuvanje zdravlja nude još jednu veoma važnu i kvalitetnu opicju, a to je uparivanje sa drugim uređajima.

Korisnik može na vrlo jednostavan način da svoju health aplikaciju sa mobilnog telefona upari sa, na primer, Health watch uređajem i tako dobije dodatne opcije, kao što su praćenje otkucaja srca i krvnog pritiska za vreme vežbanja, što su jako važni zdravstveni parametri. Osim ovog postoje još mnogi primeri povezivanja uređaja kod health-a. Neki od njih su fitnes narukvice koje zadaju dnevne zadatke korisnicima, zatim razne vrste holtera za praćenje rada srca, kao i pametne vage, koje daju informaciju o telesnoj težini korisnika, što kasnije omogućava lakše praćenje napretka. Sve ove funkcije dale su motiv za pisanje rada, odnosno dovele su do potrebe da se kvalitet njihove upotrebljivosti i prilagođenosti korisniku ispita, kako bi sami korisnici mogli jednostavnije i kvalitetnije da koriste ovakve aplikacije. 


\section{METODOLOGIJE}

Za ispitivanje kvaliteta aplikacija kao i različitih vrsta sajtova postoji par raznovrsnih metodologija. U ovom radu biće korišćena tehnika Cognitive walkthrough koja se pokazala kao najkvalitetnija u sličnim radovima. Dodatno, u ovom poglavlju rad će se baviti analizom tehnika za ispitivanje kao i razlozima zbog kojih je Cognitive walkthrough najbolji izbor.

\subsection{Izbor i analiza metodologija}

Metode inspekcije aplikacija pojavile su se kao dodatna verzija metodama testiranja početkom devedesetih godina 20. veka. Koristeći metode inspekcije ocenjivač, u pravilu HCI stručnjak, procenjuje usklađenost interaktivnog sistema $\mathrm{s}$ važećim standardima i smernicama upotrebljivosti. Najčešće korišćene metode inspekcije su: evaluacija po heuristikama i kognitivni prolazak.

Evaluacija po heuristikama predstavlja jednu od dve najpoznatije i najkvalitetnije tehnike za inspekciju upotrebljivosti aplikacija. Ona radi po principu pregleda sistema i utvrđivanja dobrih i loših elemenata, odnosno funkcionalnosti istog. Upoređuje se kompletan sistem neke aplikacije sa smernicama upotrebljivosti koje su unapred određene. Tokom sprovođenja postupka heurističkog vrednovanja svaki ocenjivač prolazi kroz elemente sistema najmanje dva puta. Prilikom prvog prolaska samo se upoznaje sa radom aplikacije i njenim mogućnostima. Drugi prolazak služi za ocenjivanje funkcionalnosti i određenih elemenata sistema na osnovu ranije dobijenog spiska heuristika. Na kraju se dobija konačan spisak funkcionalnosti koje u manjoj ili većoj meri nisu ispoštovale heuristike. Postoji deset heuristika spram kojih se vrednuje kvalitet upotrebljivosti aplikacije. Heuristike vrednovanja su [1]: vidljivost statusa sistema, usaglašenost sistema sa realnim svetom, kontrola i sloboda u korišćenju, konzistentnost i standardi, prevencija grešaka, prepoznavanje pre pamćenja, fleksibilnost $\mathrm{i}$ efikasnost korišćenja, estetski i minimalistički dizajn, prepoznavanje $\mathrm{i}$ oporavak od grešaka i pomoć $\mathrm{i}$ dokumentacija. Date heuristike potrebno je ispoštovati u celosti kako bi aplikacija bila na visokom nivou upotrebljivosti. Nakon sprovodjenja tehnike evaluacije po heuristikama korisnik koji testira aplikaciju treba da navede gde se tačno problem pojavio kao i koja konkretno od heuristika je prekršena. Osnovna prednost ovakvog tipa ispitivanja aplikacija jeste mogućnost njene primene u svim fazama razvoja aplikacije, kao i brza i efikasna identifikacija, kako glavnih tako i sporednih problema upotrebljivosti [2].

Pored dve osnovne metode ispitivanja postoji još jedna, manje zastupljena, koja takođe daje dobre rezultate. Formalan pregled upotrebljivosti je formalizovana metoda za pregled pristupa kao i identifikovanje i opisivanje problema upotrebljivosti. Namenjena je timu evaluatora, čiji članovi se stavljaju u ulogu HCI stručnjaka. Pomoću metode ujedno se utvrđuju potencijalne performanse korisnika pri izvođenju zadataka. Metoda ima sedeće karakteristike: utvrđivanje i opis problema upotrebljivosti, veliki tim evaluatora gde svaki ima svoj zadatak i opisuje zaseban deo aplikacije i struktura životnog ciklusa upotrebljivosti, odnosno šest logičkih koraka ispitivanja koji osiguravaju da se identifikacija i opis problema upotrebljivosti obavi na učinkovit i kvalitetan način.

\subsection{Cognitive walkthrough}

U ovom radu analiza upotrebljivosti Mobile Health aplikacija biće sprovedena metodologijom Cognitive walkthrough ili tehnikom kognitivne šetnje. Metoda se zasniva na teorijskoj osnovi kognitivne teorije učenja kroz istraživanje. To je pristup upotrebljivosti specifičan za zadatak (za razliku od heurističke evaluacije koja je holističnija inspekcija upotrebljivosti).

Ideja počiva na tome da većina korisnika radije uči nove stvari na osnovu praktičnog primera, nego čitajući priručnik ili prateći niz uputstava. Metoda kognitivnog prolaska namenjena je evaluatorima koji simuliraju ponašanje korisnika tokom rešavanja zadataka u sistemu. Sastoji se od dve faze: pripreme i izvođenja. Faza pripreme je navođenje konkretnih koraka koji treba da se ispitaju da bi se utvrdila upotrebljivost aplikacije. Druga faza odnosi se na traženje odgovora na četiri osnovna pitanja tehnike kognitivnog prolaska. Pitanja na koja je potrebno odgovoriti su [3]:

- Da li će korisnik postići očekivani efekat?

- Da li će korisnik uočiti da je očekivana radnja moguća?

- Da li korisnik povezuje adekvatnu akciju sa rezultatom koji želi da postigne?

- Ako je akcija uspešno izvedena, može li korisnik uočiti napredak ka konačnom rešenju zadatka?

Potrebno je da korisnik odgovori detaljno na svako od postavljenih pitanja, kako bi dobio što je moguće preciznije rezultate. Prednosti metode kognitivnog prolaska uključuju delotvornu identifikaciju problema koji proizlaze iz interakcije $\mathrm{s}$ aplikacijom i usko su povezani s lakoćom učenja aplikacije, te mogućnosti utvrđivanja korisničkih ciljeva i ponašanja prilikom korišćenja aplikacije. S druge strane, složenost metode i preterana detaljnost u sprovođenju spadaju u glavne nedostatke ove metodologije.

\section{INSPEKCIJA APLIKACIJA}

U ovom poglavlju biće sprovedena inspekcija upotrebljivosti funkcionalnosti Samsung i Huawei health aplikacija. Funkcionalnosti koje će biti ispitane su: izbor fizičke aktivnosti kod obe aplikacije, unos kalorija kod Samsung health-a i konekcija sa drugim uređajima kod Huawei health aplikacije.

\subsection{Fizička aktivnost}

Osnovna i najvažnija funkcionalnost health aplikacija jeste fizička aktivnost. Svrha postojanja ove vrste aplikacija ogleda se u potrebi čoveka za dobrim izgledom i u što većoj meri zdravim životom.

Sama analiza upotrebljivosti za izbor fizičke aktivnosti biće sprovedena kroz obe aplikacije. U slučaju Samsungove ona se sprovodi kroz osam koraka: izbora kartice gde je prikazana željena aktivnost, izbor prikaza, unos vrednosti koju korisnik želi da dostigne, klik na dugme gde piše započni, klik na dugme gde piše pauza, klik na dugme gde piše završi, odlazak na padajući meni gde piše svi pribori, izbor kartice u istoriji aktivnosti koju korisnik želi da pregleda. Svaki od oivh koraka potrebno je analizirati tehnikom kognitivnog prolaska. Odnosno dobiti odgovore na sva četiri osnovna pitanja metodologije Cognitive walkthrough. 
$\mathrm{Na}$ osnovu detaljne analize utvrđeno je da prva četiri koraka u potpunosti zadovoljavaju uslove postavljene datim pitanjima. Za razliku od njih, peti korak narušava većinu kriterijuma. Korisnik u momentu treniranja nema na početnom ekranu opciju da završi aktivnost, što zapravo narušava kriterijum prva tri pitanja. Korisniku je potrebno prethodno iskustvo sa datom aplikacijom da bi znao da mora prvo da izabere opciju pauze, da bi nakon toga mogao da zaustavi merenje svih parametara u toku treninga. Pored toga na drugo pitanje je nemoguće odgovoriti pozitivno, jer se odmah pored dugmeta za pauzu nalazi dugme za zaključavanje, predstavljeno slikom katanca (slika 1), što korisnika može da dovede u stanje konfuzije i nemogućnosti da razazna koju opciju treba izabrati da bi došao u situaciju da završi aktivnost. Takođe, samim tim što jedna od opcija nije na početnom ekranu već u startu je dati kriterijum narušen. Treće pitanje takođe nije zadovoljeno iz istih razloga kao i prethodna dva.

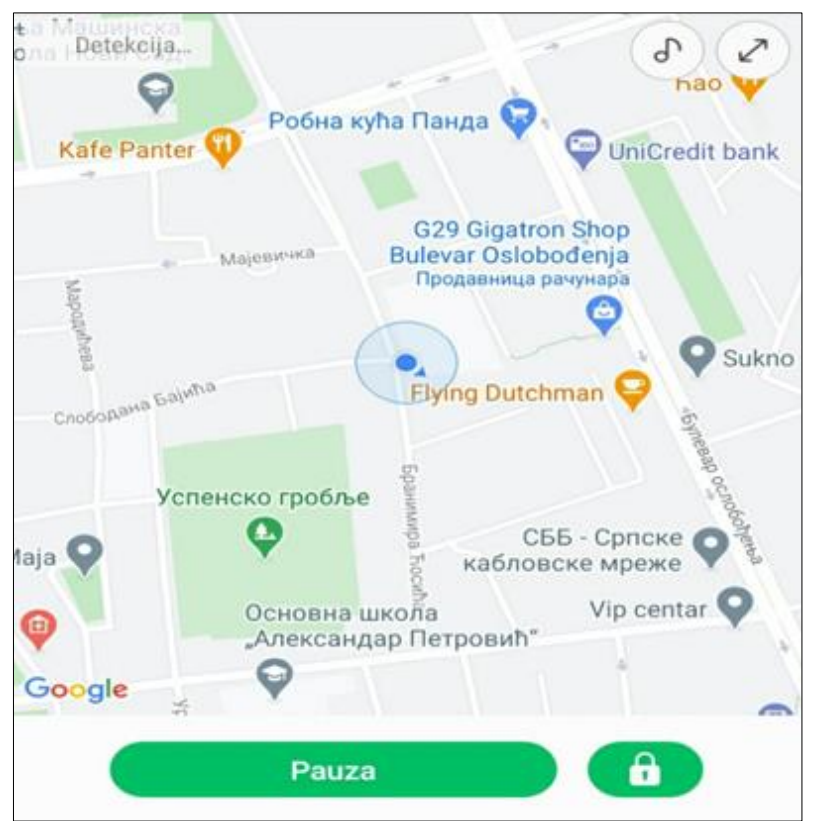

Slika 1. Ekran sa komandama za pauzu i zaključavanje

Nakon analize Samsungove funkcionalnosti za izbor fizičke aktivnosti u okviru ovog poglavlja vrši se i analiza iste funkcionalnosti, samo ovoga puta kod Huawei healtha. Koraci za izvršavanje ove akcije su: izbor taba exercise, odabir željene vrste vežbanja, klik na dugme za pokretanje akcije, klik na dugme za pauzu i zadržavanje dugmeta za prekid akcije uz potvrdu izlaska. Kao i kod Samsung-a, svaki korak potrebno je detaljno analizirati kako bi se utvrdio kvalitet upotrebljivosti.

Da se primetiti da za razliku od prethodno analizirane aplikacije, ova ima manji broj koraka za analizu. Razlog za ovu pojavu leži u tome što u slučaju Huawei health-a funkcionalnosti izbora fizičke aktivnosti i pregleda istorije aktivnosti predstavljaju dve potpuno odvojene opcije. U ovom radu analizirana je samo funkcionalnost izbora fizičke aktivnosti. Nakon njene detaljne analize utvrđeno je da se u dva od pet koraka javljaju odstupanja od kriterijuma upotrebljivosti, ustanovljenog tehnikom kognitivnog prolaska. Prvi korak u potpunosti zadovoljava sva četiri postavljena pitanja. Za razliku od njega u drugom koraku dolazi do kršenja četvrtog kriterijuma upotrebljivosti.
Nakon izbora fizičke aktivnosti koju korisnik želi da upražnjava, na ekranu ostaju prikazane i ostale aktivnosti iz ponude, sa tom razlikom da je izabrana vežba podvučena. Ovo ne daje očekivani odgovor na četvrto pitanje, jer povratna informacija o izboru aktivnosti nije urađena na adekvatan način. Korisnik, naročito onaj $u$ starijem životnom dobu, neće sa lakoćom primetiti koju je vežbu izabrao, što može dovesti do nepotrebnog gubljenja vremena za ponovni izbor. Treći korak je najkvalitetnije urađen i dao je pozitivne odgovore na sva pitanja. U slučaju četvrtog koraka javlja se isti problem kao i kod Samsung health aplikacije, da se prvo mora izabrati opcija pauze, da bi se mogla napustiti vežba.

Takođe je prikazana i zbunjujuća opcija zaključavanja kao i još jedna dodatna opcija, takođe nepotrebna. Na posletku javlja se i narušavanje trećeg kriterijuma u okviru poslednjeg koraka. Ono se ogleda u tome da korisnik mora da zadrži dugme za izlazak iz datog ekrana, iako ono izgleda kao obično dugme za klik, uz to da nigde nije naglašeno da je dugme potrebno duže zadržati. Ovo daje negativan odgovor na treće pitanje, jer korisnik koji dođe do željenog ekrana i koji želi da zaustavi akciju koja traje, može da dođe u situaciju da ne zna na koji način to da izvrši. Na slici 2 prikazan je ekran sa dugmetom za izlazak, koje je potrebno zadržati, kao i dugmetom za eventualni nastavak akcije.

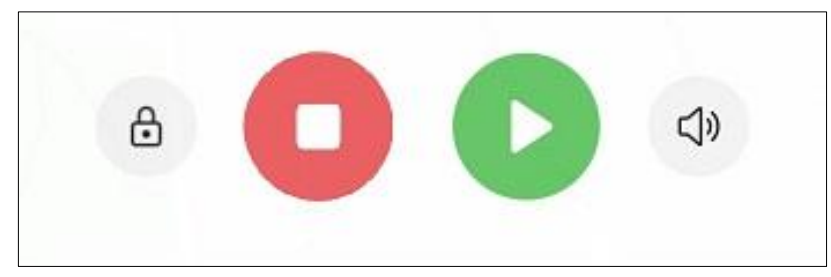

Slika 2. Ekran sa komandama za nastavak i prekid akcije

\subsection{Praćenje kalorijskog unosa}

Praćenje kalorijskog unosa je funkcionalnost koja ne postoji u okviru Huawei health aplikacije, odnosno to je funkcionalnost za koju će se sprovesti analiza isključivo Samsung health-a. Kao što je fizička aktivnost glavna karakteristika health aplikacija kada je potrošnja kalorija u pitanju, tako je unos hrane glavna kada su unešene kalorije u pitanju. Kada je reč o unosu obroka u okviru Samsung health-a, postupak se odvija iterativno na sledeći način: klik na sekciju sa izborom hrane, odabir tipa obroka, unos naziva željene hrane u pretragu, klik na željenu hranu i klik na dugme na kome piše gotovo.

Ovaj postupak zapravo predstavlja unos pojedinačnih namirnica, odnosno neće se njime samim po sebi dobiti celokupan obrok. Međutim, sam postupak unosa obroka je iterativni postupak unosa namirnica, tako da nije bilo potrebe objašnjavati isti algoritam nebrojeno puta.

Kada je reč o samoj analizi porebno je istaći da se ovaj postupak sastoji se iz pet koraka. Velikim delom daje pozitivne odgovore na pitanja ustanovljena tehnikom kognitivnog prolaska. Jedino u okviru drugog koraka dolazi do narušavanja drugog kriterijuma. Razlog za to je taj što su u okviru prikaza obroka presdtavljene tri vrste užine, iako je dovoljna i samo jedna, a dodatnu konfuziju unosi činjenica da su sve prikazane istom sličicom. 


\subsection{Veza sa drugim uređajima za očuvanje zdravlja}

U ovom poglavlju biće izvršena inspekcija upotrebljivosti funkcionalnosti za uparivanje sa drugim uređajima. Povezanost sa drugim uređajima za očuvanje zdravlja predstavlja funkcionalnost koju ima Huawei health aplikacjia, dok Samsung health nema. Odnosno Samsungovi uređaji se povezuju međusobno na potpuno drugačiji način, koji nije tema ovog rada.

Koraci za povezivanje sa drugim uređajima su sledeći: izbor taba devices, odabir opcije za dodavanje novog uređaja, izbor vrste uređaja za dodavanje, klik na željeni uređaj uz potvrdu izbora.

Kompletan postupak sastoji se iz četiri koraka i veoma je jednostavan. Svaki korak u potpunosti zadovoljava sve kriterijume tehnike Cognitive walkthrough, zbog čega detaljnija analiza ove funkcionalnosti nije potrebna.

\section{DISKUSIJA I POREĐENJE REZULTATA}

Nakon detaljne analize svih funkcionalnosti Samsung i Huawei health aplikacija, potrebno je prikazati rezultate, diskutovati određena poboljšanja, kao i u ovom slučaju, koji to dozvoljava, uporediti slične ili iste funkcionalnosti i njihove rezultate.

Analiza je pokazala da su funkcionalnosti izbora fizičke aktivnosti dveju aplikacija veoma slične, kao i da se njihove razlike oslikavaju u finesama. Jedina razlika koja pravi prednost u korist Samsung-ove aplikacije jeste ta što se kod Huawei health-a pri prekidu aktivnosti mora zadržati dugme duže, što narušava treći kriterijum kognitivnog prolaska. Prednost kod Huawei-ja je ta što je istorija aktivnosti zasebna funkcionalnost, pa se korisnik može lakše snaći pri izboru. Sve ostalo se uglavnom poklapa.

Pored poređenja dveju istih funkcionalnosti, različitih aplikacija, u ovom poglavlju je potrebno i dati određena rešenja problema. Za sve navedene nedostatke moguće je na vrlo jednostavan način pronaći rešenja.

Za izbor aktivnosti kod Samsung-a, rešenje bi moglo da predstavlja dodavanje dugmeta za nasilno prekidanje akcije na početni ekran (slika 3 ).

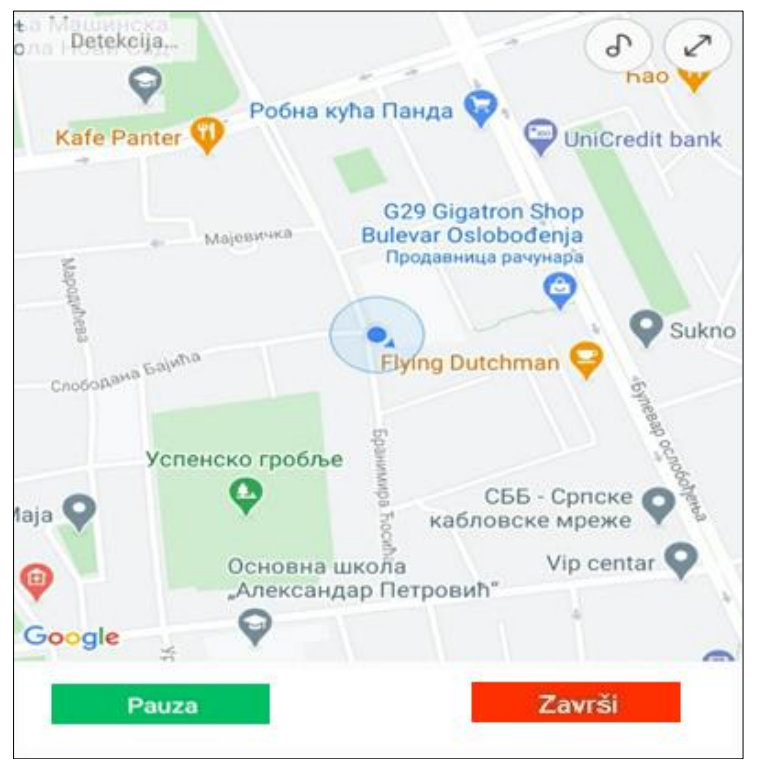

Slika 3. Ekran sa mogućim rešenjem za prekid akcije
Isti je slučaj i kod Huawei health-a. Jedina razlika je u tome što je ovde potrebno pronaći rešenje i za dugme za prekid akcije. Konkretno rešenje je vrlo jednostavno i intuitivno $\mathrm{i}$ ogleda se $\mathrm{u}$ tome da se treba promeniti zadržavanje dugmeta u klik.

Na posletku problem kod unosa kalorija je takođe vrlo lako rešiv. Postoje dva moguća rešenja. Prvo je da se dve užine obrišu i ostavi se mogućnost izbora samo jedne. Drugo, manje kvalitetno, je da se svaka užina predstavi različitom slikom $i$ da se tako spreči mogućnost da korisnik dođe u stanje konfuzije.

\section{ZAKLJUČAK}

U radu je opisan problem analize dveju health aplikacija i poređenja njihovih rezultata, pomoću metodologije Cognitive walkthrough.

Glavni razlog izbora ove teme jeste taj što su health aplikacije široko primenjive u današnjem svetu. Pored toga, veoma su popularne među ljudima koji se aktivno bave treningom, ali i onima koji veliku pažnju posvećuju svom zdravlju.

Analiza samih aplikacija sprovedena je tehnikom kognitivnog prolaska. Ova tehnika se oslanja na lično iskustvo evaluatora i kao takva je mnogo popularnija od drugih metodologija. Svaka funkcionalnost ispitana je na osnovu četiri osnovna pitanja ove tehnike.

Funkcionalnosti ispitivane u okviru ovog rada su: izbor aktivnosti i načina vežbanja kod obe aplikacije, unos kalorija kod Samsung health aplikacije i veza sa drugim uređajima kod Huawei health aplikacije.

Kao i svaki rad ovog tipa i ovaj ima određene nedostatke i prostor za unapređenje. Tu se pre svega misli na mali broj ispitanih funkcionalnosti, ali i na prisustvo samo jednog evaluatora. Savet za buduća unapređenja je da se ispitaju funkcionalnosti praćenja telesne težine, ali i izmene profila, koje su zajedničke za obe aplikacije. Pored toga bilo bi poželjno da se broj evaluatora poveća makar na tri, kao i da se ispita bar još jedna aplikacija.

\section{LITERATURA}

[1] Jakob Nielsen i Rolf Molich ,Heuristic evaluation of user interfaces“, april 1990.

[2] Jakob Nielsen ,, Usability inspection methods”, april 1994.

[3] Cognitive walkthrough, https://medium.c/evaluationof-a-user-interface-using-cognitive-walkthrough-realcase-ac94014003d8

\section{Kratka biografija:}

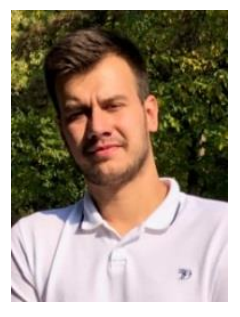

Nemanja Vujović rođen je 1996. godine u Novom Sadu. Završio je gimnaziju ,Jovan Jovanović Zmaj" takođe u Novom Sadu 2015. godine. Diplomirao je na Fakultetu tehničkih nauka u Novom Sadu 2019. godine $\mathrm{i}$ iste godine je upisao Master studije na smeru Računarstvo i automatika. kontakt: vujovicnemanja670@gmail.com 